\title{
Enhancing the dissolution rate of mefenamic acid with solid dispersion system using avicel PH-101
}

\author{
Widyasari Putranti ${ }^{*}$,Lina Widiyastuti, Fitri Ulfani \\ Faculty of Pharmacy, Universitas Ahmad Dahlan Yogyakarta \\ Jl. Prof. Soepomo, S.H.,Janturan, Yogyakarta
}

Submitted: 04-12-2018

Reviewed: 25-01-2019

Accepted: 08-03-2019

\begin{abstract}
Mefenamic acid, based on the Biopharmaceutics Classification System (BCS), is a class II drug that has high permeability but low water solubility. To improve its intrinsic dissolution rate, it is usually combined with a hydrophilic and porous drug carrier like Avicel to create a solid dispersion. This study aimed to enhance the intrinsic dissolution rate of mefenamic acid using a solid dispersion with Avicel PH-101. The test of intrinsic dissolution rate involved a rotational speed of $60 \mathrm{rpm}$ and $\mathrm{CO}_{2}$-free water with a temperature of $37^{\circ} \mathrm{C}$ as a medium. The interaction of mefenamic acid and Avicel PH-101 was analyzed with FTIR and DSC spectroscopy. The test results showed that the intrinsic dissolution rates (in $\mathrm{mg}_{\mathrm{cm}} \mathrm{cm}^{-2} \cdot$ minute ${ }^{-1}$ ) of three replications of mefenamic acid, solid dispersion of mefenamic acid and avicel PH-101 (SDMA) with 1:1 ratio, SDMA with 1:2 ratio, Physical Mixture of Mefenamic Acid and Avicel PH-101 (PMMA) with 1:1 ratio, and PMMA with 1:2 ratio were $\left(8.0 \times 10^{-4} \pm 3.0 \times 10^{-4}\right),\left(38.0 \times 10^{-4} \pm 3.0 \times 10^{-4}\right),\left(67.0 \times 10^{-4} \pm\right.$ $\left.10.0 \times 10^{-4}\right),\left(20.0 \times 10^{-4} \pm 6.0 \times 10^{-4}\right)$, and $\left(44.0 \times 10^{-4} \pm 14.0 \times 10^{-4}\right)$, respectively. The interaction between mefenamic acid and Avicel PH-101 created a hydrogen bonding, as evidenced by the shift in the peaks of FTIR spectra. Based on the DSC thermogram, the mefenamic acid-Avicel PH-101 interaction shifted the steep peak on the curve of mefenamic acid slightly. Avicel PH-101 in this solid dispersion can increase the intrinsic dissolution rate of mefenamic acid through hydrogen bonding instead of decreasing its crystalline structure into an amorphous form.
\end{abstract}

Keywords: Avicel PH-101, intrinsic dissolution, mefenamic acid, solid dispersion

\footnotetext{
*Corresponding author:

Widyasari Putranti

Faculty of Pharmacy, Universitas Ahmad Dahlan Yogyakarta

Jl. Prof. Soepomo, S.H.,Janturan, Yogyakarta

Email: widyasari@pharm.uad.ac.id
} 


\section{INTRODUCTION}

Drug solubility is the major determinant of not only drug formulation and its future development but also its therapeutic efficacy (Vemula et al., 2010). Class II drugs in the Biopharmaceutics Classification System (BCS) have low solubility but high permeability, and drug dissolution controls drug absorption (Krishnaiah, 2010).

Mefenamic acid is a nonsteroidal anti-inflammatory drug (NSAID) belonging to BCS class II drugs (Vikram et al., 2012). It has poor water solubility that ranges from $0.004 \mathrm{mg} / \mathrm{mL}$ at $37^{\circ} \mathrm{C}$ (Patil et al., 2010) to $0.2 \mathrm{mg} / \mathrm{mL}$ at $25^{\circ} \mathrm{C}$ (Swathi et al., 2011). However, it is highly soluble in hydrophilic organic solvents, such as ethanol $\left(14.8 \mathrm{mg} / \mathrm{mL}\right.$ at $\left.25^{\circ} \mathrm{C}\right)$ and polyethylene glycol 400 $\left(11.5 \mathrm{mg} / \mathrm{mL}\right.$ at $\left.25^{\circ} \mathrm{C}\right)$ (Swathi et al., 2011). Water solubility that determines the dissolution rate of mefenamic acid is a primary factor in its bioavailability (Vikram et al., 2012).

Solid dispersion is one of the promising methods for increasing the solubility and dissolution rate of poorly water-soluble drugs. It disperses one or more active ingredients in an inert carrier by melting, solvent, or melting-solvent technique (Pamudji et al., 2014). Solid dispersions can be created with polymers such as polyvinylpyrrolidone, polyethylene glycol, polyvinylpyrrolidone-vinyl acetate copolymers, sodium starch glycolate, Avicel, CAB-O-SIL, and crospovidone. Based on the previous in-vivo test, Surface Solid Dispersion (SSD), which employs solvent deposition technique, has been proven to increase drug release profile, resulting in bioavailability with a rapid onset of action (Khatry et al., 2013).

Avicel is a hydrophilic filler that tends to expand and absorb water very well (wicking mechanism) (Saigal et al., 2009). The mixture of drugs and hydrophilic carriers (i.e., polymers) induces high wettability by reducing the surface tension between the drug particles and the dissolution medium and, thereby, increasing the interfacial area of contact between them. As a result, drug solubility improves (Modi and Tayade, 2006).

Intrinsic dissolution rate is defined as the rate at which drug particles dissolve under the interfacial area that depends on stirring speed and the acidity $(\mathrm{pH})$ and constant ionic strength of the dissolution medium. An effective intrinsic dissolution rate is depicted as a mass transfer from a solid surface to the liquid phase (Dezani et al., 2013).

This research aimed to determine the intrinsic dissolution rate of the solid dispersion of mefenamic acid and Avicel PH-101 and analyze their interaction.

\section{MATERIALS AND METHOD \\ Materials}

The tools used in this study included an analytic balance (EX225D Explorer, Ohaus), UV1800 spectrophotometer (Shimadzu), FTIR spectrophotometer (Thermo Scientific Nicolet iS 10), DSC-60 Plus, hotplate and stirrer (LMS-1003; Labtech), mixer motor (RW 20; IKA), the Wood's dissolution tool that had been modified by Yuwono, pellet printing device (4350 L; Carver), and water bath (Memmert).

The main materials and ingredients used in this study were mefenamic acid (pharmaceutical degree; PT. Brataco, Bekasi), Avicel PH-101 (pharmaceutical degree; PT. Brataco, Bekasi), $\mathrm{NaOH}$ (analytical degree; PT. Merck Indonesia), ethanol 96\% (pharmaceutical degree; PT. Brataco, Bekasi), and distilled water.

\section{Methods \\ Identification of wavelength of maximum absorbance ( $\lambda \mathbf{m a x})$ of mefenamic acid}

The wavelength of maximum absorbance $(\lambda \max )$ of mefenamic acid was determined from the mefenamic acid solution in $0.1 \mathrm{~N} \mathrm{NaOH}$ with a concentration of $10 \mu \mathrm{g} / \mathrm{mL}$ (Nerdy, 2017). 


\section{Generation of the standard curve of mefenamic acid}

The absorbances of mefenamic acid solution in $0.1 \mathrm{~N} \mathrm{NaOH}$ with different concentrations, i.e., $5,7.5,10,12.5$, and $15 \mu \mathrm{g} / \mathrm{mL}$, were measured at the $\lambda \max$ of mefenamic acid and used to generate the equation of the standard curve (Nerdy, 2017).

\section{Identification of $\lambda \max$ of mefenamic acid-Avicel PH-101}

The wavelength of maximum absorbance ( $\lambda \max$ ) of mefenamic acid-Avicel PH-101 was determined from the mefenamic acid-Avicel solution (1:1) in $0.1 \mathrm{~N} \mathrm{NaOH}$ with a concentration of $10 \mu \mathrm{g} / \mathrm{mL}$.

\section{Generation of the standard curve of mefenamic acid-Avicel}

The absorbances of mefenamic acid-Avicel solution (1:1) in $0.1 \mathrm{~N} \mathrm{NaOH}$ with different concentrations, i.e., $5,7.5,10,12.5$, and $15 \mu \mathrm{g} / \mathrm{mL}$, were measured at the $\lambda \max$ of mefenamic acidAvicel PH-101 and used to generate the equation of the standard curve (Nerdy, 2017).

\section{Preparation of the solid dispersion of mefenamic acid with Avicel PH-101 (SDMA)}

The solid dispersion of mefenamic acid and Avicel PH-101 was made with two ratios using the solvent method, i.e., 1:1 and 1:2. Every $500 \mathrm{mg}$ of mefenamic acid was dissolved in $50 \mathrm{~mL}$ of ethanol 96\% and added with Avicel PH-101 while stirred (using a magnetic stirrer). Then, the solvent was evaporated in the water bath and dried in an oven at $50^{\circ} \mathrm{C}$. The mass produced in this process was sieved using a 60 mesh and then stored in a desiccator (Essa and Dwaikat, 2015).

\section{Preparation of the physical mixture of mefenamic acid and Avicel PH-101 (PMMA)}

The physical mixture of mefenamic acid and Avicel PH-101 was weighed with ratios 1:1 and 1:2, mixed without pressure, and sifted with a 60 -mesh sieve.

\section{Pellet preparation}

Pellets in the form of tablets were extruded from $300 \mathrm{mg}$ of mefenamic acid powder, SDMA, and PMMA with different ratios. The pellet printing or extrusion used a hydraulic press by applying 5 tons of pressure for 5 minutes to the mold.

\section{Test of intrinsic dissolution rate}

The topside of the pellets was poured with melted paraffin, allowing only one surface to intersect with the dissolution medium directly. The support, filled with sample, was closed and connected to the rotating motor. The dissolution tube was filled with the dissolution medium, which was $50 \mathrm{~mL}$ of $\mathrm{CO}_{2}$-free distilled water, and the temperature was set with a thermometer at $37^{\circ} \mathrm{C}$. The pellets were attached to the support, then dipped into the dissolution medium and arranged in a way that no air bubbles were present underneath. This setting was connected to the rotating motor and immediately rotated at a speed of $60 \mathrm{rpm}$. The dissolution result was sampled using a $5 \mathrm{~mL}$ pipette every 5 minutes for an hour (i.e., 5, 10, 15, 20, 25, 30, 40, 50, and 60 minutes). Each of the liquid samples had to be replaced immediately with the dissolution medium with the same volume and temperature. The absorbance of each sample was read at the $\lambda \max$ of mefenamic acid (Khairinnisa, 2007).

\section{Fourier-transform infrared (FTIR) spectroscopy}

The powder was measured with an infrared spectrophotometer using $\mathrm{KBr}$ pellets. The absorption spectrum was recorded at wavenumbers between $400-4000 \mathrm{~cm}^{-1}$ (Indra and Yulianti, 2017). The sample powder with $\mathrm{KBr}$ was crushed, transferred to the extrusion die, and pressed into 
a disc in a vacuum condition (Octavia et al., 2015). $\mathrm{KBr}$ pellets were prepared by grinding the sample with $\mathrm{KBr}$ (1\% of weight) and pressed by applying 7 tons of pressure for 5 minutes (Sammour et al., 2006).

\section{Differential scanning calorimetry (DSC)}

The DSC analyses were performed on mefenamic acid, Avicel PH-101, and the solid dispersion of mefenamic acid-Avicel PH-101 (SDMA) with the optimal ratio. Some samples were put in the pan and placed on the detector plate. Afterward, they were heated from $25^{\circ} \mathrm{C}$ to $300^{\circ} \mathrm{C}$ at a rate of $10^{\circ} \mathrm{C}$ per minute.

\section{Data Analysis}

The intrinsic dissolution rate of mefenamic acid was obtained from the slope of the linear curve, which represented the relationship between M/S (the amount of mefenamic acid dissolved per unit area) and dissolution time. The effect of the solid dispersion of mefenamic acid-Avicel PH101 (SDMA) on intrinsic dissolution rate was determined by statistically comparing the rates of mefenamic acid, SDMA with 1:1, 1:2, and 1:5 ratios and PMMA with 1:1 and 1:2 ratios in SPSS.

\section{RESULTS AND DISCUSSION \\ Standard curve of mefenamic acid}

The absorbance of $10 \mu \mathrm{g} / \mathrm{mL}$ mefenamic acid solution in $0.1 \mathrm{~N} \mathrm{NaOH}$ solution was measured with UV-Vis spectrophotometer at a wavelength ranging from $200 \mathrm{~nm}$ to $400 \mathrm{~nm}$. The observation results showed that the wavelength of the maximum absorbance ( $\lambda$ max) of mefenamic acid was $284.00 \mathrm{~nm}$; the maximum absorbance was 0.455 . The standard curve was generated from the absorbances of mefenamic acid with five different concentrations, namely $5,7.5,10,12.5$, and $15 \mu \mathrm{g} / \mathrm{mL}$. The equation of this standard curve was $\mathrm{y}=0.0424 \mathrm{x}+0.001$ with a correlation value ( $\mathrm{r}-$ count) of 1.0000. The $\mathrm{r}$-table for five samples (the number of concentration variation) with $\mathrm{df}=3$ and $95 \%$ confidence level is 0.878 . Because the $\mathrm{r}$-count is higher than r-table, there is a positive correlation between concentration and absorbance in this standard curve.

\section{The effect of avicel PH-101 on the $\lambda$ max of mefenamic acid}

The absorbance of $10 \mu \mathrm{g} / \mathrm{mL}$ mefenamic acid-Avicel PH-101 (1:1) solution in $0.1 \mathrm{~N} \mathrm{NaOH}$ solution was measured with a UV-Vis spectrophotometer at a wavelength of $200-400 \mathrm{~nm}$. The observation results showed that the $\lambda$ max of mefenamic acid was measurable, i.e., $284.80 \mathrm{~nm}$ with the maximum absorbance of 0.449. This finding explains that Avicel PH-101 shifts the $\lambda \max$ of mefenamic acid slightly and affects its absorbance. The standard curve of the solid dispersion of mefenamic acid-Avicel PH-101 was used to identify the effects of Avicel PH-101 on the absorbance of mefenamic acid. This curve was generated using the same five concentrations as mefenamic acid, namely $5,7.5,10,12.5$, and $15 \mu \mathrm{g} / \mathrm{mL}$. The equation of this standard curve was $y=0.0388 x+0.071$ with a correlation value (r-count) of 0.9949 . The $r$-table for five samples (the number of concentration variation) with $\mathrm{df}=3$ and $95 \%$ confidence level is 0.878 . Because the $r$ count is higher than r-table, there is a positive correlation between concentration and absorbance in this standard curve.

The Shapiro-Wilk normality test revealed that the data were distributed normally. Based on the Levene's test results, the data was distributed homogeneously and, therefore, subjected to further parametric paired-samples t-test. This test found that the two standard curves showed a significant difference, meaning that the addition of Avicel PH-101 can shift the wavelength and increase the absorbance of mefenamic acid considerably. To calculate the amount of dissolved mefenamic acid, this research used the linear equation of the standard curve of mefenamic acidAvicel PH-101 (1:1), i.e., $\mathrm{y}=0.0388 \mathrm{x}+0.071$. 


\section{The intrinsic dissolution rate}

The correlation curve of the dissolved mefenamic acid per unit area $(\mathrm{M} / \mathrm{S})$ and the sampling time of mefenamic acid, SDMA, and PMMA is presented in Figure 1.

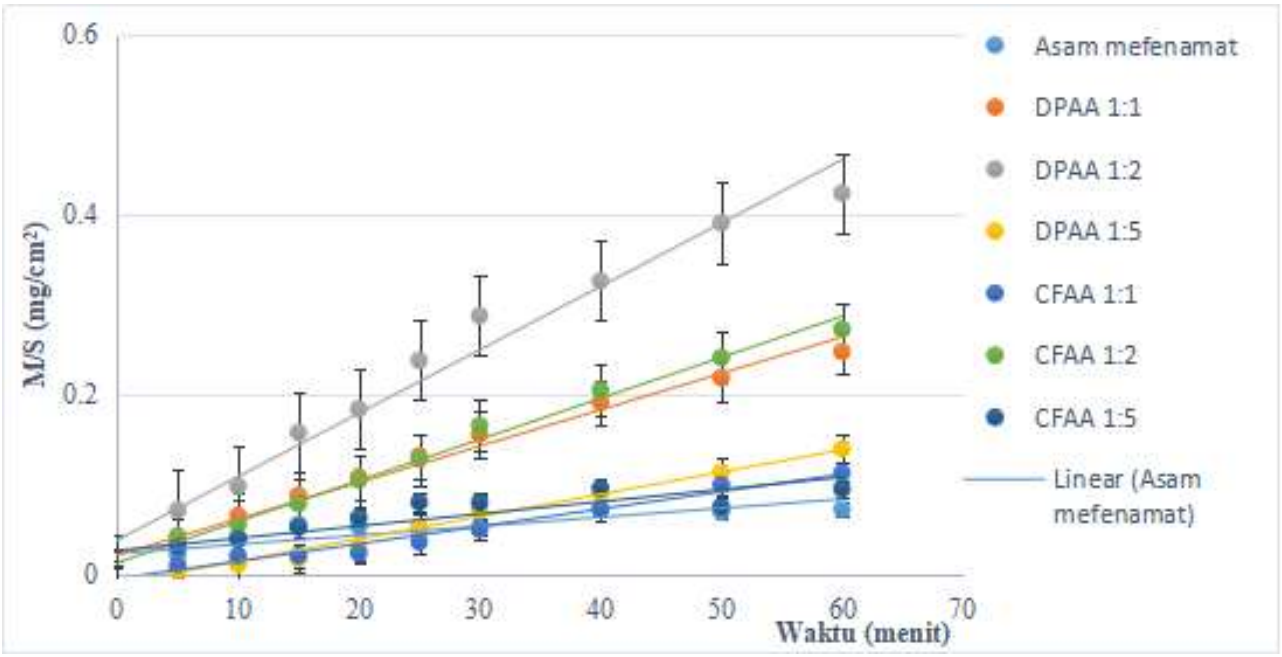

Figure 1. The correlation curve between $\mathrm{M} / \mathrm{S}$ and dissolution time

Table I shows that the samples of SDMA 1:1, SDMA 1:2, PMMA 1:1, and PMMA 1:2 significantly increase the intrinsic dissolution rate of mefenamic acid, respectively, 4.75, 8.38, 2.5, and 5.5 times the rate of pure mefenamic acid. A greater acceleration in the drug's dissolution rate is caused by the mechanism of solid dispersion that can increase the wettability and solubility of poorly water-soluble drugs (Babu and Chowdary, 2008). Avicel can enhance the dissolution of mefenamic acid with surface solid dispersion using the solvent method (Charumanee et al., 2004).

Table I. The intrinsic dissolution rates of mefenamic acid, SDMA, and PMMA

\begin{tabular}{cl}
\hline Samples & \multicolumn{1}{c}{$\begin{array}{c}\text { Average } k \\
\left(\mathrm{mg} \cdot \mathrm{cm}^{-2} . \mathrm{minute}^{-1}\right)\end{array}$} \\
\hline Mefenamic acid & $8.0 \times 10^{-4} \pm 3.0 \times 10^{-4}$ \\
SDMA 1:1 & $38.0 \times 10^{-4} \pm 3.0 \times 10^{-4} *$ \\
SDMA 1:2 & $67.0 \times 10^{-4} \pm 10.0 \times 10^{-4} *$ \\
PMMA 1:1 & $20.0 \times 10^{-4} \pm 6.0 \times 10^{-4} *$ \\
PMMA 1:2 & $44.0 \times 10^{-4} \pm 14.0 \times 10^{-4} *$ \\
\hline
\end{tabular}

Notes

* = significant difference with the intrinsic dissolution rate of mefenamic acid

Interaction of mefenamic acid and avicel PH-101 based on FTIR-spectroscopic analysis

The shift and changes in the FTIR spectra profile indicated an interaction between mefenamic acid and Avicel PH-101. The interaction is in the form of intermolecular hydrogen bonds (Figure 2) because the profile change occurred at a wavelength between 3000-3500 $\mathrm{nm}$. Figure 3 shows the wavenumbers that appear in each vibration cluster. The vibration of secondary amine groups ( $\mathrm{N}-\mathrm{H}$ stretches) commonly appears between $3100 \mathrm{~cm}^{-1}$ and $3500 \mathrm{~cm}^{-1}$ (Pavia et al., 2009). In the FTIR spectra of the mefenamic acid samples, the vibration of the N-H stretches appears at a wave number of $3306.55 \mathrm{~cm}^{-1}$. Avicel PH-101 does not have a secondary amine group, but a peak emerges at a wave number of $3331.63 \mathrm{~cm}^{-1}$, indicating hydrogen bonding on $\mathrm{O}-\mathrm{H}$ stretches. The vibration of the $\mathrm{O}-\mathrm{H}$ stretches that form hydrogen bonds is usually found between

Enhancing the dissolution ...(Putranti et al.,) 
3200 and $3570 \mathrm{~cm}^{-1}$ (Coates, 2000). The absorbance bands that indicated the vibration of secondary $\mathrm{N}-\mathrm{H}$ group in PMMA (1:2) and SDMA (1:2) appeared at wave numbers of $3306.97 \mathrm{~cm}^{-1}$ and $3307.39 \mathrm{~cm}^{-1}$, respectively. Both of these bands widened and represented overlapping bands between the secondary $\mathrm{N}-\mathrm{H}$ group of mefenamic acid and the $\mathrm{O}-\mathrm{H}$ stretches in Avicel PH-101. This finding signifies the presence of interaction between mefenamic acid and Avicel PH-101.

This conclusion is also supported by the ability of mefenamic acid and Avicel PH-101 to form hydrogen bonds with other molecules. According to Zaini et al. (2017), the solid dispersion system of genistein-PVP K-30 shows the deformation of $\mathrm{OH}$ groups in genistein because hydrogen bonds are formed between genistein and PVP K-30 polymers. In a solid dispersion system, hydrogen bonding between the drug and the carrier is highly likely.

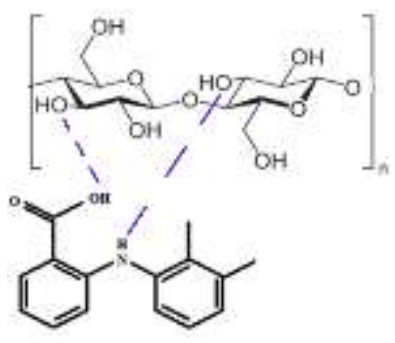

Figure 2. The model of hydrogen bonds that are potentially formed between mefenamic acid and Avicel PH-101 (the $O$ atoms in Avicel PH-1010 bonds with the $H$ atoms in the carboxylic groups and the secondary amine group in mefenamic acid)

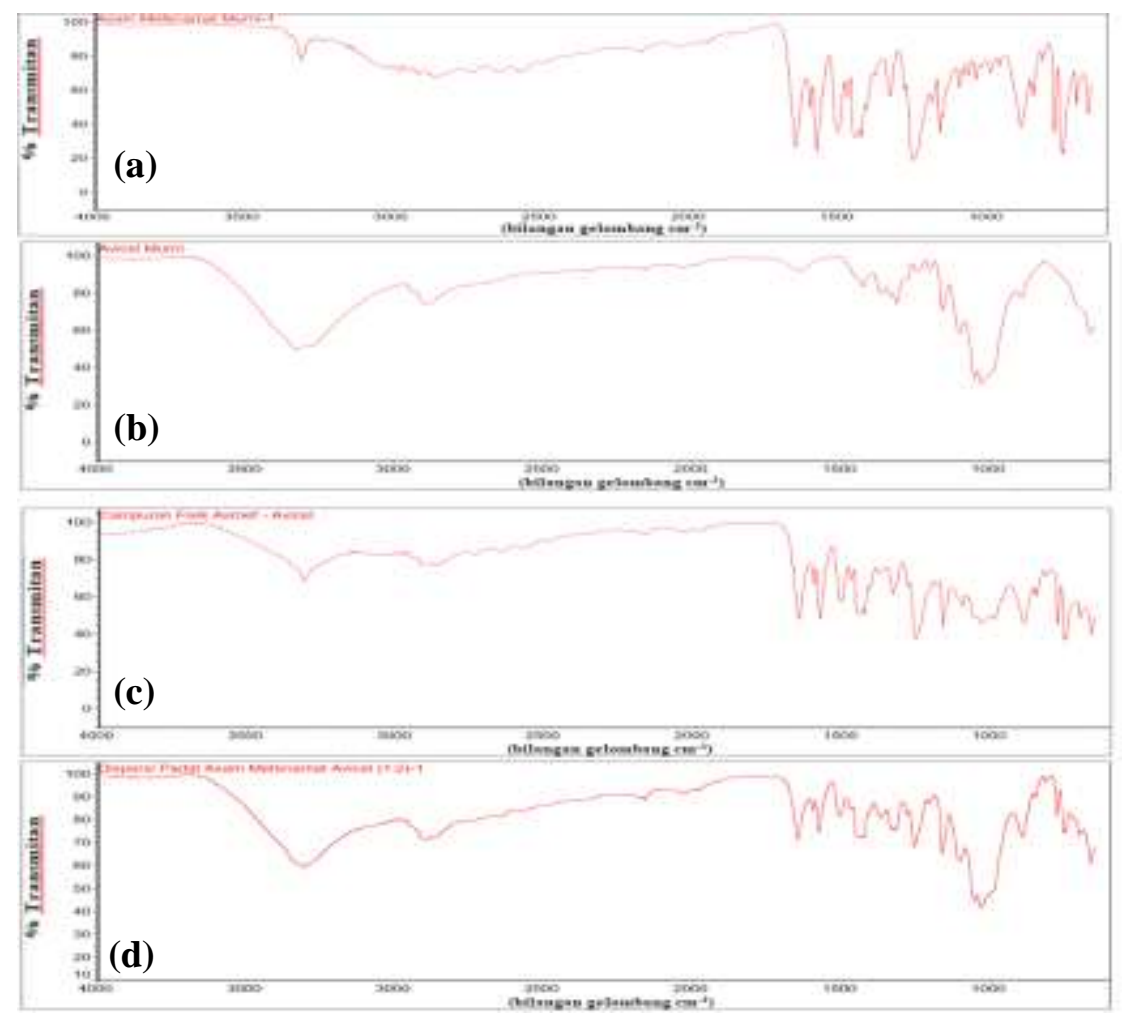

Figure 3. FTIR Spectra of (a) mefenamic acid, (b) Avicel PH-101, (c) PMMA 1:2, (d) SDMA 1:2 
The hydrogen bonds between mefenamic acid and Avicel PH-101 can occur due to the dipole-dipole action between the molecules of mefenamic acid and Avicel PH-101. The partially positive hydrogen atoms in mefenamic acid are pulled by the electron pairs of $\mathrm{O}$ atoms in the electronegative Avicel PH-101.

\section{Interaction of mefenamic acid and avicel PH-101 based on DSC Analysis}

The DSC thermogram of mefenamic acid in Figure 4 shows that its crystalline phase surpasses the steep endothermic peak at $232.36^{\circ} \mathrm{C}$ with $\Delta \mathrm{H}=-72.81 \mathrm{~J} / \mathrm{g}$. The amorphous phase of Avicel PH-101 exceeds the broad endothermic peak at $104.39^{\circ} \mathrm{C}$ with $\Delta \mathrm{H}=-90.13 \mathrm{~J} / \mathrm{g}$. The DSC thermogram of SDMA (1:2) shows that the peaks of mefenamic acid and Avicel PH-101 shift slightly, namely $103.34^{\circ} \mathrm{C}$ with $\Delta \mathrm{H}=-77.92 \mathrm{~J} / \mathrm{g}$ and $231.61^{\circ} \mathrm{C}$ with $\Delta \mathrm{H}=-12,60 \mathrm{~J} / \mathrm{g}$.

This slight shift implies that the heat or temperature needed to melt mefenamic acid in a solid dispersion (from crystalline to liquid phase) is smaller than pure mefenamic acid. The decrease in enthalpy $(\Delta \mathrm{H})$ in the solid dispersion preparation of mefenamic acid-Avicel PH-101 shows that the amount of heat energy required to break down the crystals of mefenamic acid in solid dispersion is smaller than the crystals of pure mefenamic acid. The steep peak of mefenamic acid on the DSC thermogram of the solid dispersion of mefenamic acid-Avicel PH-101 indicates that this solid dispersion does not change the crystals of mefenamic acid to their amorphous form.

Based on the FTIR spectra and DSC thermogram analysis of the interaction between mefenamic acid and Avicel PH-101, the improved intrinsic dissolution rate of SDMA is caused by the presence of intermolecular hydrogen bonds between mefenamic acid drugs and the hydrophilic carrier, that is, Avicel PH-101.

The results of this study indicated SDMA 1:1 and 1:2 can increase the intrinsic dissolution rate by 4.75 and 8.38 times compared with the pure mefenamic acid. Considering the addition of another component in the tablet formulation, the research found that the optimal ratio for tablet formulation was SDMA 1:1. 

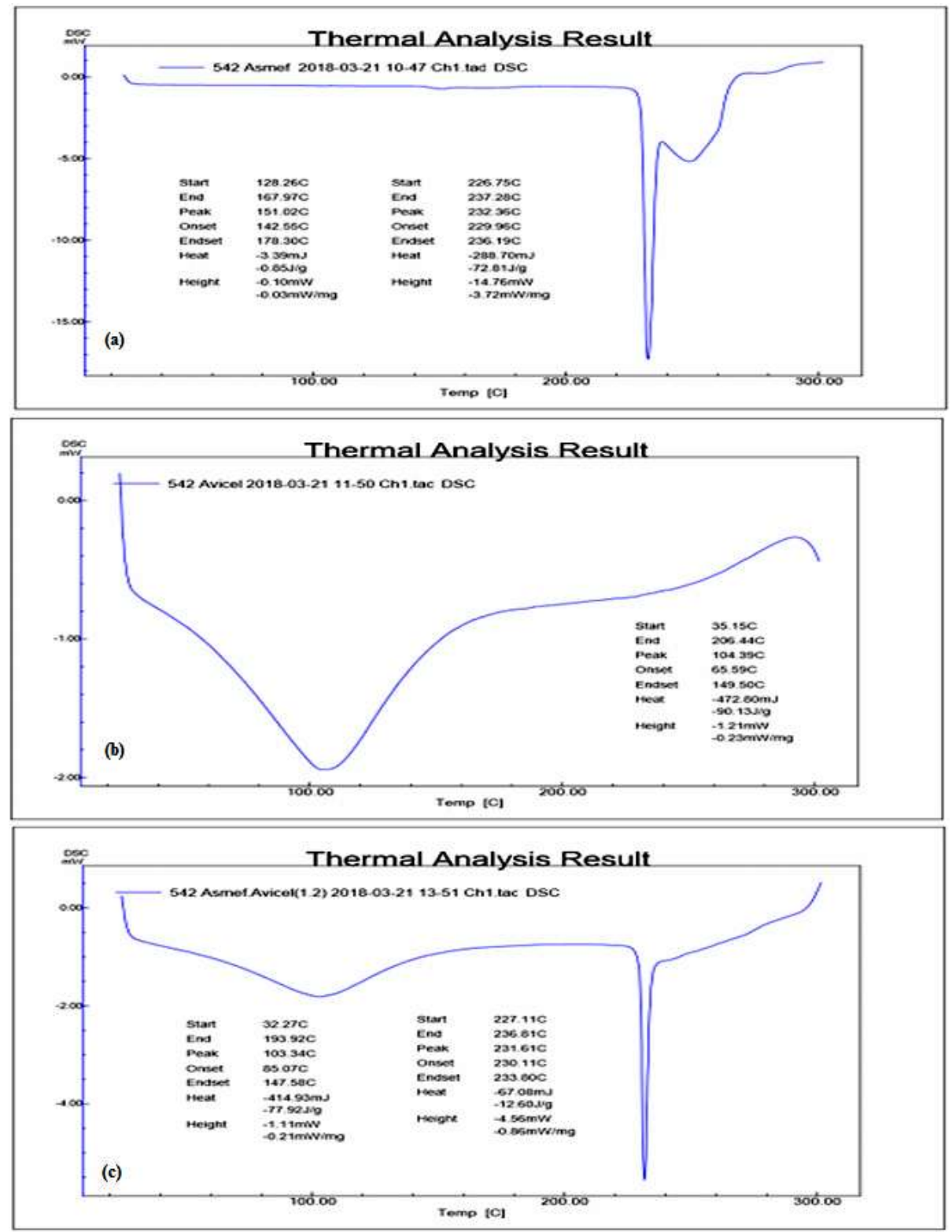

Figure 4. The DSC Thermograms of (a) mefenamic acid, (b) Avicel PH-101, (c) SDMA 1:2

\section{CONCLUSION}

Preparing a solid dispersion of mefenamic acid using the carrier Avicel PH-101 with a ratio 1:1 can increase the intrinsic dissolution rate of mefenamic acid significantly compared to that of pure mefenamic acid because the interaction between mefenamic acid and Avicel PH-101 creates hydrogen bonding instead of transforming the crystals in mefenamic acid into their amorphous state.

\section{ACKNOWLEDGMENT}

Authors would like to thank the Research and Community Service Institute, Universitas Ahmad Dahlan Yogyakarta for their financial assistance through the scheme of fundamental grant. 


\section{REFERENCES}

Babu PS and Chowdary KPR, 2008, Enhancement of dissolution rate of celecoxib by solid dispersion in superdisintegrant. Indian Drugs, 45:547-552.

Charumanee, S, Okonaki S, Sirithunyalug, J, 2004. Improvement of Dissolution rate of piroxicam by Surface Solid Dispersion. CMU Jurnal, 3:77-84.

Coates, J., 2000, Interpretation of Infrared Spectra. A Practical Approach. In Encyclopedia of Analytical Chemistry, in R.A. Meyers (Ed.), pp. 1085-10837, John Wiley \& Sons Ltd,Chichester, UK.

Dezani, A.B., Pereira, T.M., Caffaro, A.M., Reis, J.M., Helena, C., Serra, R., 2013, Equilibrium Solubility Versus Intrinsic Dissolution: Characterization of Lamivudin, Stavudine and Zidovudine for BCS Classification, Brazilian Journal of Pharmaceutical Sciences, 49 (4) : 853-863.

Essa A.E, Dwaikat,M. 2015. Enhancement of Simvastatin Dissolution by Surface Solid Dispersion: Effect of Carriers and Wetting Agent, Journal of Applied Pharmaceutical Science, 5 (Suppl 1):046-053.

Indra and Yulianti, R., 2017 Karakterisasi Padatan Hasil Proses Kokristalisasi Asam Mefenamat menggunakan Metode Penguapan Pelarut, Jurnal Kesehatan Bakti Tunas Husada, 17 (1) : 21-24.

Khatry, S., Sood, N., Arora, S., 2013, Surface Solid Dispersion - A Review, International Journal of Pharmaceutical Sciences and Nanotechnology, 6 (1): 1915-1924.

Khairinnisa, I.N., 2007, Peningkatan Kecepatan Disolusi Intrinsik Ibuprofen melalui Pembentukan Dispersi Padat dengan PEG 6000, Skripsi, Fakultas Farmasi Universitas Ahmad Dahlan.

Krishnaiah, Y.S.R., 2010, Pharmaceutical Technologies for Enhancing Oral Bioavailability of Poorly Soluble Drugs, Journal of Bioequivalence \& Bioavailability, 2 (2): 28-33.

Modi, A., and Tayade, P., 2006, Enhancement of Dissolution Profile by Solid Dispersion (Kneading) Technique, American Association of Pharmaceutical Scientist Pharmaceutical Science and Technology, 7 (3): Article 68.

Nerdy, 2017, Validation of Ultraviolet Spectrophotometry Method for Determination of Mefenamic Acid Level in Suspension Dosage Forms, Jurnal Natural, 17 (1): 17-22.

Octavia, M.D., Zaini, E., Oktavia, V., 2015, Studi Sistem Dipersi Padat Asam Mefenamat Menggunakan Polivinilpirolidon K-30, Jurnal Farmasi Higea, 7 (2): 173-180.

Pamudji, J.S., Wikarsa, S., Tampara, M.H., 2014, Improvement of Glicazide's Dissolution of Rate by Using Surface Solid Dispersion with Avicel PH-101, International Journal of Pharmacy and Pharmaceutical Sciences, 6 (11): 461-465.

Patil, P.B., Gupta, V.R.M., Udupi, R.H., Srikant, K., Prasad, B.S.G., 2010, Development of Dissolution Medium for Poorly Water Soluble Drug Mefenamic Acid, Research Journal of Pharmaceutical, Biological and Chemical Sciences, 1 (4): 546-548.

Pavia, D.L., Lampman, G.M, and Kriz-Jr, G.S., 2009, Introduction to Spectroscopy: A Guide for Student of Organic Chemistry, W.B. Saunders Company, Philadelphia, USA.

Saigal, N., Boboota, S., Ali, J., 2009, Microcrystalline Cellulose as a Versatile Excipient in Drug Research, Journal of Young Pharmacist, 1 (1): 6-12.

Sammour, O.A., Hammad, M.A., Megrab, N.A., Zidan, A.S., 2006, Formulation and Optimization of Mouth Dissolve Tablets Containing Rofecoxib Solid Dispersion, American Association of Pharmaceutical Scientists, 7 (2): 55.

Swathi C.H., Subrahmanyam, C.V.S., Kedarnath, S.A., Babu, P.R.S., 2011, Solubilization of Mefenamic Acid, International Journal of Pharmacy and Technology, 3 (3): 3267-3276.

Vemula, V.R., Lagishetty, V., Lingala, S., 2010, Solubility Enhancement Techniques, International Journal of Pharmaceutical Sciences Review and Research, 5 (1) : 41-46.

Vikram, A., Firoz, S., Kishore, D., Mouli Y.C., Venkataramudu, T., 2012, Formulation and Evaluation of Mefenamic Acid Tablets by Using Modified Starch, Asian Journal of Pharmaceutical Science \& Technology, 2 (2): 46-53. 
Zaini, E., Putri,V.Z., Octavia M.N., Ismed, F., 2017. Peningkatan Laju disolusi dispersi padat amorf Genistein dengan PVP K-3. Jurnal Sains Farmasi \& klinis, 4(2) 67-72. 